\title{
Building the required skillsets for a resilient public health workforce: A decade of field epidemiology training in Ghana
}

Ghana Med J 2020; 54(2) supplement: 1-2 DOI: http://dx.doi.org/10.4314/gmj.v54i2s.1

The emergence and re-emergence of infectious and non-infectious diseases is a major issue of public health concern. The outbreak of Ebola, Lassa Fever, Meningitis and the ongoing COVID-19 pandemic has highlighted the need to have a multisectoral public health workforce with the requisite skillsets to effectively address these situations.

As part of the strategies to build these skillsets for public health professionals, the United States Centers for Disease Control and Prevention (US CDC) has assisted countries and territories to establish Field Epidemiology Training Programs. The aim of the FETP training is to provide the public health workforces with the ability to prevent, early detect and respond to threats with the skills to collect, analyse and interrupt disease information so that prompt action can be taken to save lives. ${ }^{1,2}$

In 2007, with support for US CDC, Ghana established a two-year advanced level competency-based Field Epidemiology and Laboratory Training Programme (FELTP) at the University of Ghana School Of Public Health in collaboration with national stakeholders such as the Ministry of Health, Ghana Health Service and Veterinary Service Department. The aim of the programme is to address the critical gap in the public health workforce skills required for early detection, response and mitigation of outbreaks and other public health emergencies. ${ }^{3}$

Built on the One-Health Concept, residents are selected from the animal, human and environmental sector. The training approach is $20-25 \%$ of didactics (classroom work) and 75-80\% on-the-job experiential learning and service provision. The rationale is to foster teamwork and strong collaborations in the fight against all kinds of public health threats which are mostly complex and required a multidisciplinary effort from these professionals.

The GFELTP currently runs the CDC three-tiered pyramid model namely: Frontline, Intermediate, and Advanced programmes. The tiered approach to training ensures that the training needs of the various levels of the health system are addressed. At each of the tier, competencies are built in public health surveillance; surveillance data analysis; outbreak investigation and response; epidemiologic methods and scientific communication.
Over the past decade, residents and alumni of the programme have used the acquired competencies to conduct more than 250 surveillance system evaluation and surveillance data analyses, and close to 200 outbreak investigations at national, regional and district levels. Notably among these investigations is the ongoing COVID-19 pandemic, 2019 Polio outbreaks and the 2016 protracted cholera outbreak in Central region and Anthrax outbreaks in Northern region.

Scientific communication which is a critical competency each trainee is expected to acquire before the end of their training has equipped residents and alumni to effectively communicate their public health findings at local and international platforms. In addition, findings have been documented and shared with necessary stakeholders to inform decision making and improve the existing systems.

This supplement is the evidence of the scientific communication competencies trainees have gained over their learning period. Reports from surveillance system evaluations, surveillance data analysis, outbreak investigations and planned studies have been developed into manuscripts and published in scientific journals. In this supplement, we share a cross section of peer reviewed papers on the fieldworks of residents and graduates of the GFELTP with the scientific community in Ghana, Africa and the world at large.

The scope of these papers ranges from outbreak investigations, surveillance system evaluations, surveillance data analysis, and planned epidemiologic studies. These manuscripts were written through manuscript writing workshops and mentorships held to develop scientific communication skills of trainees by learning to translate field reports into public health communication pieces.

\section{References}

1. US CDC. Global Health Protection and Security; About FETP. US CDC. Atlanta. 2018. Available: https://www.cdc.gov/globalhealth/ healthprotection/fetp/about.html (assessed: 29 May, 2020)

2. Traicoff DA, Walke HT, Jones DS, Godstad EK, Imtiaz R. White ME. Replicating Success: Developing a Standard FETP Curriculum. Public Health Rep. 2008; 123(Suppl 1): 28-34. 
3. Ameme DK, Nyarko KM, Kenu E, Afari EA. Strengthening surveillance and response to public health emergencies in the West African subregion: the role of Ghana FELTP. Pan Afr Med J. 2016;25 (Supp 1):1.
Ernest Kenu, Delia A. Bandoh, Basil B. Kaburi and Samuel O. Sackey

Ghana Field Epidemiology and Laboratory Training Program, School of Public Health, University of Ghana, Accra

Email: EKenu@ug.edu.gh 